\title{
Not on the Same Page: Undergraduates' Information Retrieval in Electronic and Print Books
}

\author{
Selinda Adelle Berg \\ Clinical Medicine Librarian \\ University of Windsor \\ Windsor, Ontario, Canada \\ sberg@uwindsor.ca \\ Kristin Hoffmann \\ Head, Research \& Instructional Services \\ The University of Western Ontario \\ London, Ontario, Canada \\ khoffma8@uwo.ca \\ Diane Dawson \\ Natural Sciences Liaison Librarian \\ University of Saskatchewan \\ Saskatoon, Saskatchewan, Canada \\ diane.dawson@usask.ca
}

\begin{abstract}
Academic libraries are increasingly collecting e-books, but little research has investigated how students use e-books compared to print texts. This study used a prompted think-aloud method to gain an understanding of the information retrieval behavior of students in both formats. Qualitative analysis identified themes that will inform instruction and collection practices.
\end{abstract}

\section{INTRODUCTION}

Academic libraries are increasingly developing electronic collections as a means to better serve library users. The growth and dominance of the Internet in daily life, as well as the increasing investments in distance education programs, have contributed to an overall heightened focus on electronic resources. Electronic journals (e-journals) have achieved widespread and enthusiastic acceptance within the scientific disciplines of the higher education community, and are now an integral part of academic science library collections. ${ }^{1}$ Much of the optimism for the success of electronic books (e-books) seems to stem from linked assumptions that the convenience, usability, and approbation of e-journals will be paralleled in e-books. E-book collections are thus being developed in response to expectations for point-of-need accessibility in the same way that e-journals have. Although the pervasive success of e-journals is generally assumed to be transferable to e-books, anecdotal evidence suggests that current e-books may not in fact offer the same convenience or usability as e-journals. Numerous e-book platforms and reading devices have been developed in recent years and have been surrounded by considerable hype, however, users continue to favor print books. ${ }^{2}$ As well-known digital libraries scholar and critic, Karen Coyle, argues, "[w]e are collecting materials in electronic format and digitizing books without 
having a clear idea of how they will be used."3 For example, usability and functionality are clearly important to the uptake of e-books, yet there is limited research that explores how students actually use e-books compared with traditional uses of print books.

In response to this absence of scholarship, this study observes and compares the strategies of undergraduate science students performing information retrieval tasks in e-books and in print books. Such a comparative perspective will contribute to our understanding of informationseeking behavior and information uses in a digital environment, as well as help inform collection management at a time when librarians are increasingly presented with choices concerning the purchase of competing e-book packages from publishers and consortia.

\section{LITERATURE REVIEW}

The growing interest and investment in e-books in academic libraries during the last decade has spurred a considerable amount of literature in this area. Numerous news and opinion pieces have been published in the Library and Information Science literature concerning, in particular, the hype surrounding e-books, discussions about various reader devices, and speculation over the possible future of this technology. ${ }^{4}$ There is also an accumulating body of collection management-oriented studies which analyze e-book usage statistics across various parameters (such as subject areas, user groups, and timelines). ${ }^{5}$ It is beyond the scope of this literature review to provide an overview of each of these areas; instead we will concentrate specifically on selected articles related to two themes: the attitudes of academic library users with respect to ebooks, and experimental e-book usability research. Additionally, we will also review selected literature related to the think-aloud methodology used in this research.

\section{Attitudes Towards E-books}

So far, much of the literature about user attitudes towards e-books has consisted of surveys and focus groups gauging the opinions of the academic community and library professionals. Such surveys have reported an assortment of attitudes ranging from enthusiastic support to indifference and skepticism. Strengths of e-books and potential areas for improvement have also been identified.

Although the current cohort of undergraduate students belongs to the tech-savvy Millennial generation, there is conflicting evidence regarding students' acceptance of e-books. Research indicates that although users appreciate the convenience and accessibility of e-books, the potential for e-books to function as a value-added resource remains unclear. Studies have indicated that search functionality and navigation are critical to users' approval of e-books. ${ }^{6}$ An international survey of college and university students conducted in 2008 by ebrary confirmed what many librarians had suspected: students claim the most important features of e-books to be those related to searching and anytime/anywhere access. ${ }^{7}$ Similarly, Michael Levine-Clark's survey of library users found that more than half of the respondents mentioned that the most beneficial aspect of e-books was the inclusion of a search function. Levine-Clark also reported that many respondents only read portions of e-books; such realities underline the importance of

searching and navigation. ${ }^{8}$ The interactive features of e-book platforms (such as search capabilities) are potentially the most significant advantage that e-books have over print books.

Cynthia Gregory's survey investigating undergraduates' attitudes towards e-books also found that although students liked the convenience, cost, and print-ability of e-books, they expressed concern with perceived eyestrain and reported confusion about certain navigation and 
search functions. ${ }^{9}$ Eyestrain or fatigue from reading on a computer screen for a prolonged time is perhaps the most common usability complaint from e-book users and has been scientifically substantiated by Kang, Wang and Lin. ${ }^{10}$

In addition to the general uncertainty about using e-books, research also indicates that students tend to be unaware as to whether or not e-books are even available at their institution. Both the ebrary surveys and the results of a Joint Information Systems Committee (JISC) survey indicate that many students do not know if their libraries offer e-books, nor do they know how or where to access them. ${ }^{11}$ Furthermore, Levine-Clark reported users' confusion as to what actually constitutes an e-book. ${ }^{12}$ One of the possible reasons for the slow uptake and acceptance of ebooks in academic institutions may then be due to a lack of promotion and instruction on the part of libraries. ${ }^{13}$ Although e-book awareness and usage is generally lower than anticipated, many non-e-book users express a desire to learn more about e-books. ${ }^{14}$ Strategies identified in the literature for promoting the use of e-books include embedding them within online or virtual learning environments such as course websites or course management systems, user training for e-books, and direct promotion to faculty members. ${ }^{15}$

\section{E-book Usability Experiments}

There have been few studies that experimentally explore how students use e-books compared to their use of the traditional print format. However, several studies have employed empirical techniques to assess e-book usability by recruiting participants and asking them to complete information retrieval tasks in e-books.

An early series of experiments, collectively called the "WEB Book Experiments", evaluated how electronic textbook design can affect users' engagement with the material. Researchers concluded that a successful e-book can be produced by combining good web design with aspects of well-designed paper books: users reacted positively to e-books that visually resembled print books, but also expected web functionalities such as searching and hyperlinks. ${ }^{16}$ The objective of these experiments was ultimately to produce a set of best practice guidelines for designing electronic textbooks for the academic user. The guidelines of Electronic Books ONscreen Interface (EBONI) discuss numerous e-book usability issues related to on-screen design and hardware design. ${ }^{17}$

More recently, Abdullah and Gibb published the results of a series of investigations into e-book usability issues. ${ }^{18}$ The first study surveyed students about their awareness and usage of ebooks. The second study of the series explored students' reactions while they interacted with ebooks. The participants indicated that they preferred using a print book for extensive reading, but e-books were useful for selective reading and reference purposes. The final experiment investigated three searching and browsing tools available in e-books: full text searching, table of contents, and "back of the book index." The researchers determined that the index was the most efficient tool for finding information, and performed the best overall for accurately finding relevant content in e-books.

Hernon et al. investigated how undergraduate students in the disciplines of economics, nursing, and literature use e-books. ${ }^{19}$ Similar to the survey results discussed earlier, students in this experiment reported that they liked the convenience of e-books - particularly the ability to access an electronic version of a print book that may be checked out by another user. They also liked the ability to copy and paste text into a word processing document, and the cost savings involved in not having to purchase the books for classes. However, participants did not want to read e-books in their entirety, but rather preferred to browse or scan content. The students 
became frustrated with limitations of the display, especially when images were slow to load. Hernon et al. speculated that these frustrations may be partially responsible for the reluctance to read online.

\section{Think-Aloud Method}

In order to capture and understand the ways in which students progress through information retrieval tasks in the electronic book format, compared with print books, we adopted the prompted think-aloud method. The think-aloud method is a form of concurrent verbal protocol described in 1984 by psychologists Ericsson and Simon to capture information from subjects as they perform a task. ${ }^{20}$ This method allows immediate access to the decision-making and information-gathering behavior of participants. In contrast, retrospective protocols (i.e., questionnaires, surveys, or focus groups) rely on subjects to recall their prior experiences. The time elapsed between the actual experiences and participants' reports can introduce a large amount of subjectivity and interpretation into the collected data. This subjectivity can potentially have a negative effect on the usefulness of the information gathered. The accuracy and completeness of the participant's memory also affects the quality of the data collected. While retrospective protocols can provide valuable information concerning overall impressions and opinions regarding e-books, there are limitations in providing an accurate insight into how the resources are actually being used.

Ericsson and Simon suggest that after the initial instructions are given, the researcher should interact as little as possible with the subject. This method was developed primarily for use in cognitive psychology experiments where it was assumed that the presence and interaction of the researcher could influence the data retrieved. ${ }^{21}$ However, in their study to evaluate e-learning, Cotton and Gresty suggest that the researcher's presence does not negate the value of the type of data that was collected, and they developed a "prompted think-aloud" method with more flexibility. Instead of collecting a rambling discourse from their participants, Cotton and Gresty attempted to collect more meaningful data by prompting them with a range of questions related to the type of information needed (e. g., "How are you deciding where to go?"). ${ }^{22}$ Such prompted interaction is unlikely to negatively impact the quality of data collected and has the potential to enhance their usefulness and relevancy.

\section{METHODOLOGY}

This study used a prompted think-aloud methodology and qualitative analysis techniques to examine and contrast the ways that students use e-books versus print books. The methodology was pilot tested and revised based on feedback prior to the commencement of the study. The study received ethical approval from The University of Western Ontario's Non-Medical Research Ethics Board.

\section{Participants}

A convenience sample of twenty undergraduate students currently enrolled in Faculty of Science programs at The University of Western Ontario in London, Ontario, Canada, were recruited for

the study. ${ }^{23}$ The Faculty of Science is supported by the Taylor Library, ${ }^{24}$ which has a growing collection of e-books on a variety of e-book platforms. The researchers chose this user group because undergraduate science students are expected to be heavy users of e-books. ${ }^{25}$ 
The nature of qualitative research limits the sample size. The number of participants recruited for this study was determined by estimating the number of participants needed to reach the point of saturation. The point of saturation is interpreted as the point where no new information is gained and no new themes emerge with additional subjects and further analysis. ${ }^{26}$ The sample size was established with consideration of the number of information retrieval tasks performed per participant, the scope of study, the nature of the study, and the qualitative method used. $^{27}$ As anticipated, the point of saturation was easily reached with the rich data that was captured in the total of 160 tasks completed by 20 individuals (eight tasks per participant).

The twenty students were recruited to participate in the research study through informational posters placed on bulletin boards throughout the library as well as near lecture halls and classrooms. Researchers also visited several undergraduate science classes to promote the study. All participants ( 9 male and 11 female) had completed at least two years of their programs at the point of data collection, and twelve reported that they had used an e-book prior to participating in the study.

\section{Information Retrieval Tasks and Books}

Each participant was asked to think aloud while carrying out eight information retrieval tasks, using eight books, four of which were provided as print books and four as e-books. The eight titles selected for this study were available at Taylor Library in both electronic and print formats. One information retrieval task was developed for each of the selected books. The list of books and tasks is given in Table 1. The tasks involved searching for discrete pieces of information or general sections in the book, and could be completed via several conceivable methods. This kind of information retrieval task is known as "fact searching." ${ }^{28}$ Such tasks approximate the tendency of students in the sciences to skim through texts in search of such discrete pieces of information. Each participant completed four tasks using e-books and four with print books. By the end of the study, each task was completed an equal number of times in both print books and e-books, and each of the participants saw a different combination of the eight titles in print and electronic format. Half of the participants performed tasks in print books first, and half began with tasks in e-books.

The purpose of this study is not to evaluate a particular platform, but rather to observe student usage of e-books in direct comparison to print books. Therefore, in order to reduce the number of variables introduced into the study, books were chosen that were all available electronically on the same platform. ${ }^{29}$ Comparison of various e-book platforms is beyond the scope of the present study. Although it was not a requirement for participation in the study, no participant had prior experience with the chosen platform. The platform is accessed through a web browser, with no need for additional software downloads, and the e-books are exact replicas of print versions, with each page reproduced in pdf.

\section{Data Collection}

Participants were provided with print books that had been pre-selected for them, a laptop computer to access the e-books, and a list of the tasks to be performed in each book. Participants were instructed to verbalize all thoughts while performing the assigned tasks. Completion of the tasks was videotaped by one researcher in order to capture both the verbalization and actions of the participants. Video recordings were limited to capturing the audio of the think-aloud and 


\section{Table 1}

Tasks and Books Used in the Study

\section{Task}

\section{Book}

1. Find information about the "Alexander Technique" in alleviating chronic pain.

Banks, Carol, and Karen Mackrodt, eds. Chronic

Pain Management. Philadelphia: Whurr Publishers, 2005.

2. Find information about which animal models are used in asthma research.

Falus, András. Immunogenomics and Human Disease. Chichester, Hoboken, NJ: John Wiley, 2006.

3. Find a summary table that outlines the USDA soil classification system.

Fang, Hsai-Yang and John Daniels. Introductory Geotechnical Engineering: An Environmental Perspective. New York: Taylor \& Francis, 2006.

4. Do both the genus and species names of an organism need to be capitalized?

Matthews, Janice R. and Robert W. Matthews. Successful Scientific Writing: A Step-by-Step Guide for the Biological and Medical Sciences. 3rd ed. Cambridge: Cambridge University Press, 2008.

5. What are the effects of DichloroNorris, David O. and James A. Carr, eds. Diphenyl-Trichloroethane (DDT) on eggshell formation in birds?

Endocrine Disruption: Biological Basis for

Health Effects in Wildlife and Humans. Oxford: Oxford University Press, 2006.

6. What is the difference between WiFi and Bluetooth?

Walls, Colin. Embedded Software: The Works. Boston: Elsevier/Newnes, 2006.

7. What are the indoor air contaminants Wigle, Donald T. Child Health and the associated with children's asthma? Environment. Oxford: Oxford University Press, 2003.

8. Find information about the relationship between garlic and heart disease.

Wildman, Robert E. C., ed. Handbook of Nutraceuticals and Functional Foods. Boca Raton, FL: CRC Press, 2001.

filming the computer screen or book pages of the print books in order to accurately document information retrieval strategies and participant behavior. These data were supplemented by the notes taken during the session by a second researcher. The third researcher facilitated the session and prompted the participant to think aloud while performing the assigned tasks.

An exit survey was administered at the end of the session to collect information regarding participants' previous use and knowledge of e-books, as well as their general attitudes and impressions towards e-books. 


\section{Data Analysis}

Researchers followed the six steps of thematic analysis outlined by Braun and Clarke. ${ }^{30}$ Data sources for the analysis included a demographic intake questionnaire, video recordings, verbatim transcripts, and the researchers' written notes made while participants were completing the tasks. Each researcher independently reviewed the data and generated initial codes. Initial coding allowed researchers to identify and code interesting features of the data, and collect relevant data into the codes. The researchers highlighted key statements or actions which they considered to be significant statements reflecting the essence of participants' information retrieval experience with the two formats. Individual researchers then collated initial codes into potential themes before reconvening to review, identify, and name the final themes. Although there was a high degree of consistency between the researchers' initial codes and themes, any researcher inconsistencies within data analysis and theme generation were thoroughly discussed until consensus was achieved.

\section{QUALITATIVE THEMES}

From qualitative analysis of the data collected, researchers identified four themes relating to information retrieval in electronic and print books. The four themes emerging from the qualitative data were: (Non)Linear Strategies, (In)Tangible Volumes, (Un)Met Expectations, and (Non)Transferable Behaviors.

\section{(Non)Linear Strategies: "Hopefully I will find something doing this"}

Linear describes a process that progresses sequentially "in a single direction by regular steps or stages." 31 The degree to which participants followed a linear or direct process was collected under the theme (Non)Linear Strategies.

Participants used linear approaches when seeking information in print books. When they were assigned a task and given the corresponding book in print format, they began to pursue a discrete information retrieval strategy. The linear approach consisted of the following steps: identifying keywords; looking for those words in the table of contents or index; turning to the designated page of the book; and scanning for relevant content. Participants consistently followed this strategy through to completion of the task.

When participants were unsuccessful in their initial attempt, they thought creatively about new keywords, applied knowledge gathered in the information retrieval process, and repeated the linear process described above. In the following quotation, the participant is using the table of contents to find the answer. Although he does not find his initial search term ("Alexander Technique") in the table of contents, he continues to use the table of contents, but with new terms:

"Alexander Technique or if there's anything similar to that ... so ... " mumbles through chapter headings

“... it's not in the [table of contents] so it's going to be hard to find, um, [pause] at this stage I would probably look online and look up what's the Alexander Technique under, and so at least I would have roughly an idea of what kind of, of whether it's pharmacopharmacological technique, or is it some sort of therapy? Actually, it probably would fall under therapy." 
points to chapter containing the term therapy

"Can look up that and see if I could find it ... 258"

goes to page

"complementary therapy"

scans text, finds heading for Alexander Technique

"Okay, got it"

- Participant G completing task \#1 in print book

In contrast, participants working with e-books did not follow a linear path. They did not progress seamlessly from keyword identification to discrete information retrieval strategy, but rather appeared unsure as to how to approach the task. Participants pursued and abandoned multiple methods. They did not choose a strategy and follow it to completion, but rather abandoned search strategies when faced with obstacles. The following transcript demonstrates the lack of linearity in the information-seeking process in e-books:

"I am just browsing through the contents and I see that they have a chapter on Garlic, Chapter 12"

"I will go back to the search again"

unsuccessfully searches for the words: garlic heart disease

- Participant J completing task \#8 in e-book

After multiple attempts with multiple strategies in the electronic environment, participants often expressed that they hoped to serendipitously come across the information. This uncertainty may be due to a lack of familiarity with the technology. The quotation below followed multiple attempts to find the information and reveals that the participant searching in ebooks is not certain that she will find the information:

"So I am just going to go there and hopefully find something"

- Participant L completing task \#6 in e-book

\section{(In)Tangible Volumes: "How am I going to access this thing?"}

Print books have an obvious physicality — an ability to be touched and held. In contrast, e-books are not tangible volumes and lack the ability to touched, held, and carried. Participants in the study highlighted the tangibility of print books and the intangibility of e-books in their information-seeking behaviors. Participants made use of the physicality of the print book from the onset of the task. When researchers presented the print book to participants, they routinely picked up the book and made observations about the volume, such as a comment about the title, length, or structure of the book. After initial observations, participants were able to move seamlessly and intuitively into the information-seeking task, turning to either the front of the book (table of contents) or the back of the book (index).

The physicality of the print book affected the way participants interacted with it. Participants essentially used the tangibility of the print book as an information-seeking aid. The physicality of the print book facilitated participants' awareness of where they were within the 
book and within the text on the page. Participants used their fingers to bookmark specific locations in the book and to track their reading on the page as they moved through the text. The transcript below demonstrates how the tangibility of the print book is used as a finding aid:

reads the question aloud, picks up book, reads the spine, and opens the book

"I am just going to look in the index at the back of the book because it is easier"

"I'm looking for DDT."

holds finger on the words DDT, looks back at task description

"on eggshell formation"

finger tracks as words in the DDT section of index are read; pauses

"eggshell thinning... so..."

keeps finger in index and flips through the book; scans text

"yes, it talks a bit about eggshell formation."

- Participant A completing task \#5 in print book

Progression through the print book was starkly contrasted with the experiences in the intangible e-book. Participants were brought to the introductory page of the e-book, but were unable to make immediate observations about the length, style, or structure of the book. Many participants were unable to immediately start working through the task because they were uncertain of how to open the book; they often overlooked or did not immediately recognize points of entry into the book.

While intangible e-books lack many of the print books' physical aids for informationseeking, the researchers witnessed participants' attempts to mimic the practices of the tangible print environment. For example, the act of tracking with one's finger while reading was mimicked in the online environment by using the mouse or cursor to track the electronic text. Additionally, participants attempted to overcome perceived sluggishness in moving through the book by decreasing the magnification or attempting to view two pages at once. Unlike the print books, which allowed participants to move through the book quickly by flipping through and scanning the text, participants reported that moving through e-books was cumbersome and slow. Study participants viewed this inability to move quickly as an obstacle to the use of e-books:

"I would always choose the electronic version unless I needed to look at a large amount of text as I was writing or flip back and forth between several pages."

- Participant A after completing tasks in e-books

\section{(Un)Met Expectations: “I can't click it”}

Participants expressed familiarity with the well-established conventions of print books, and this familiarity resulted in few unmet expectations when seeking information. Participants understood that the table of contents would be found at the front of the book and the index would be at the back of the book; therefore, they were able to progress through the print text with certainty. Participants were able to navigate print books successfully and confidently, and had no 
need to orient themselves to the layout prior to embarking on the information-seeking task. The following quotation illustrates how print books met a participant's expectations:

\section{flips through the book}

"Ok, um, this one doesn't look like it has an index, looks like it has a lot of references though."

flips past the references

"Uh, doo-doo-doo, ah, it does have an index!"

"This is why I love science books because they always have an index"

\section{- Participant S completing task \#4 in print book}

Participants articulated a set of expectations for e-books, even though few of them had extensive experience with the format. In the absence of an established convention for e-books, participants' expectations appeared to be modeled after the common functionality of websites. Ebooks, however, were not able to meet the wide range of expectations posed by participants, as demonstrated in the following quotation:

"I expected more from electronic books, like keyword searching, advanced searching and lots of cross-referencing"

\section{-Participant $\mathrm{G}$ after completing tasks in e-books}

The hyperlinking, or "cross-referencing," of key terms and phrases is a norm within websites; consequently, participants expected that e-books would have similar hyperlinking. They expected that all chapter titles, keywords, indexed terms and page numbers would be hyperlinked. "This is not clickable" was a common participant observation. Throughout the study, the participants consistently compared the accessibility and functionality of the e-book platform to the features of Google Books. One participant asked if he needed to "go to Google Books now" when first trying to access and open the e-book. This statement reinforces the farreaching influences of known technologies such as Google.

\section{(Non)Transferable Behaviors: "I didn't think that there was an index"}

In some instances, the researchers observed similar behaviors by participants using both print and electronic books, behaviors which appeared to be transferable between the two formats. For example, when given the task and the book, independent of the format, most participants' initial step was to identify keywords to apply to the information task. Many participants identified words from the task description, while others drew on prior knowledge of the subject area and came up with related concepts. During the task, all participants articulated keywords or paraphrased the question asked.

However, other behaviors appeared to be much less transferable between the formats. The index appeared to be the most direct strategy used in print books and was viewed as an easy way to get at the information:

"Because I'm not good at this stuff I'm probably going to go to the index at this point"

$$
\text { - Participant A completing task \#6 in print book }
$$


In contrast, participants very rarely used the index as an information-seeking tool in ebooks. Use of the index was the method least likely to be transferred from print to electronic. Many participants expressed surprise when discovering that the e-book included an index, suggesting that perhaps they do not see e-books as an exact duplication of print books. Word recognition when scanning text also did not appear to transfer well to the electronic environment. Independent of format (electronic or print) or tool (index, table of contents, search function) it was necessary for participants to scan the text for keywords and phrases. However, they missed or skipped over keywords in chapter titles, indexes, and paragraphs more often in ebooks than in print books:

searches for "soil classification" and clicks the first result, which is for the List of Tables

"I am looking for soil classification"

scans text; overlooks table titled "USDA soil classification system"

- Participant S completing task \#3 in e-book

E-books have an additional option of a search function, which is not transferable to print books. Participants showed a strong preference for conducting searches in e-books. However, many participants also became frustrated with the nature and structure of the search function, since it did not work like a Google search.

\section{DISCUSSION}

Contrary to popular expectations, although the current generation of undergraduate students is highly computer literate, they do not intuitively know how to navigate and use e-books effectively. Our findings reveal significant differences between experiences with print and electronic books. These differences are reflected in the themes: (Non)Linear Strategies, (In)Tangible Volumes, (Un)Met Expectations, and (Non)Transferable Behaviors.

The results of this study indicate that participants' strategies when negotiating print books were more linear than the strategies used in e-books. The more linear print book strategies appeared to be more successful. This is likely due to the participants' familiarity with the print format and hence their experience and confidence in the use of this format. Hernon et al. noted this attitude among the students in their study as well: "The participants tend to think of a book as something linear with a start, middle, and ending; some do not like the fact that the sense of linearity is lost with e-books." 32 They related this finding to the aversion that many of their participants expressed to reading an e-book cover-to-cover as they would a print book. Instead, their participants preferred browsing, scanning, and skipping around the text, suggesting a nonlinear approach to using e-books. Similarly, Chong, Lim, \& Ling found that the ease of use of an e-book by undergraduate students was highly associated with ease of skimming or scanning the text, as well as ease of navigation. ${ }^{33}$

The intangible nature of e-books, and conversely the very physical essence of print books, is a topic that is rarely discussed in the literature. Perhaps this subject is overlooked because it is so obvious. The tangibility of print books, in combination with the students' familiarity with the conventions of the print format, can actually function as a finding aid, as demonstrated in this study. This advantage was also noted by Liesaputra and Witten, who found that study participants could view several non-contiguous pages of a print book in quick succession by marking the relevant pages with their fingers and flipping back and forth between 
them. ${ }^{34}$ Participants in their study also complained of the cumbersomeness of moving through ebooks in contrast to print books. Comparing the thickness and weight of pages already read to those yet to be read in a print book is also an important cue to readers of where they are within the book. This "sense of place" can easily be lost in the transition to e-book reading. ${ }^{35}$ Such tangible characteristics of print books are difficult to simulate in electronic formats.

Interactive features of e-book platforms, such as editing tools, hyperlinks, and search capabilities, are an advantage that e-books have over print books, but these features must function well and be easily understood by the user. In particular, e-book tools are expected to function like known web technologies. Users are so familiar with ubiquitous online tools, such as the Google search function, that they become frustrated and confused when comparable technologies (i.e., e-books) do not function similarly. The participants in this study exhibited definite preconceived expectations, formed on the basis of their online experiences, regarding how e-book tools such as hyperlinking should operate. Wilson, Landoni and Gibb noticed this in their experiments as well: “...when today's reader approaches an electronic textbook, a second set of expectations inherited from the Web (in addition to expectations derived from using paper books) comes into play." 36

The apparent disconnect between participants' perceptions of print books and e-books seems to have contributed to the lack of potentially useful information retrieval methods not being transferred between the two formats. The most conspicuous example of this is the use of the index. Participants often favored the index as a tool in the print books and quite successfully used this tool, but nearly all of these same individuals did not realize that the index was available in the e-book. This disconnect is serious since the index is usually the most direct and efficient method for retrieving the information requested in the tasks, as found in Abdullah and Gibb's study as well. ${ }^{37}$ Wilson, Landoni and Gibb also noted that tables of contents were sometimes not enough when seeking very specific information, and advised that indexes should always be provided along with hyperlinks to the e-book content. ${ }^{38}$ Although the e-books used in this study provided an index, they were not hyperlinked to the content.

In addition to the four main themes observed in this study, participants also voiced a range of opinions and impressions that have been widely discussed in the literature. In particular, they exhibited some confusion as to what constitutes an e-book, and general ignorance of the fact that e-books are available through the library catalog. This lack of awareness suggests a need for more education and promotion. Despite this, participants were mostly eager and open to learn about e-books and could readily identify some very positive aspects of these resources such as their anytime/anywhere access, and the ability to search.

\section{IMPLICATIONS FOR LIBRARIES}

User education about e-books is key and should not be overlooked. Such education should focus on the features and functionality of the format; for example, students ought to be reminded that e-books have indexes and successful searching strategies should be demonstrated. User education should also promote the existence of e-books in library collections. While several participants in this study were familiar with Google Books, far fewer were aware that e-books were available through the library catalog.

Also, the usability of a given interface should be a primary consideration when investigating e-book platforms. Trials should be conducted by testing with the students and faculty who will be using the books. Librarians who have the opportunity to contribute to the design of e-book platforms should keep the principle of user-testing at the forefront. 


\section{LIMITATIONS}

While the purpose of this study is not to evaluate a particular e-book platform, the use of only one e-book platform is a limitation. The choice of one platform, though, allowed for consistency across titles, and the researchers believe that the chosen platform is representative of e-book platforms in general. Another limitation is that the researchers asked participants to search for discrete facts and sections within a book, rather than requiring them to acquire or assimilate knowledge from the books. Although it is important to understand the ways in which the format of books affects the critical thinking skills required to assimilate content from various sources, the scope of the study was limited to "fact searching," which is generally compatible with undergraduate science students' information needs. Finally, the contrived setting of the study's sessions may have led participants to act somewhat less naturally than if they had been in a more natural setting. For example, participants had no personal stake in the tasks they were asked to complete. Because they did not need the information, they may have been more patient when faced with technological problems or an unsuccessful search strategy.

\section{FUTURE STUDIES}

There are many possibilities for further research in this area, including an examination of how ebooks are used for various information needs (i.e., for assimilation of content rather than retrieval of discrete pieces of information), and expansion of the study's population to include user groups such as graduate students, faculty members, or librarians.

In general, more research is needed in order to better understand our users' interactions with e-books. In particular, what constitutes an intuitive e-book interface? Most e-books are set up to look very similar to print books, but is this the optimal structure for an e-book? Are there types of information that are more conducive to electronic format? Although this paper focuses on implications for academic libraries, further research in this area would be valuable for publishers and e-book vendors.

\section{CONCLUSION}

This study has highlighted several differences between how information retrieval tasks are carried out in print and electronic books. Students in the study appeared to understand the conventions of print books, which resulted in more direct processes for information-seeking than when using e-books; however, they were unclear about both the structure and functionality of ebooks. As librarians, we must question our assumptions about new electronic resources and how they will be used and understood by their users. E-book publishing is continuing to evolve, and throughout its evolution we must keep the user in the forefront and ensure that we are considering how their expectations, skills, and understanding of published material will affect their use of e-books. 


\section{NOTES AND REFERENCES}

${ }^{1}$ Eileen E. Brady, Sarah K. McCord, and Betty Galbraith, "Print versus Electronic Journal Use in Three Sci/Tech Disciplines: The Cultural Shift in Progress," College and Research Libraries 67 (2006): 354-363; Sally A. Rogers, "Electronic Journal Usage at Ohio State University," College and Research Libraries 62 (2001): 25-34.

${ }^{2}$ Cynthia L. Gregory, “'But I Want a Real Book': An Investigation of Undergraduates' Usage and Attitudes Toward Electronic Books," Reference \& User Services Quarterly 47 (2008): 266-73; Michael Levine-Clark, "Electronic Book Usage: A Survey at the University of Denver," Portal : Libraries and the Academy 6 (2006): 285-99.

${ }^{3}$ Karen Coyle, “E-reading,” The Journal of Academic Librarianship 34 (2008): 160.

${ }^{4}$ Coyle, 160-2; Rusty Kimball, Gary Ives and Kathy Jackson, "Comparative Usage of Science E-book and Print Collections at Texas A\&M University Libraries," Collection Management 35 (2010): 15-28; Mark R. Nelson, "Ebooks in Higher Education: Nearing the End of the Era of Hype?" Educause Review 43, no. 2 (2008): 40-56.

${ }^{5}$ For sample discussions, see Timothy P. Bailey, "Electronic Book Usage at a Master's Level I University: A Longitudinal Study," The Journal of Academic Librarianship 32 (2006): 52-9; Marilyn Christianson, "Patterns of Use of Electronic Books," Library Collections, Acquisitions, \& Technical Services 29 (2005): 351-63; Justin Littman and Lynn Silipigni Connaway, "A Circulation Analysis of Print Books and E-books in an Academic Research Library," Library Resources and Technical Services 48 (2004): 256-62; Ellen Safley, Demand for E-books in an Academic Library," Journal of Library Administration 45 (2006): 445-57.

${ }^{6}$ Gregory, 270; Levine-Clark, 292; Aline Soules, “The Shifting Landscape of E-books,” New Library World 110 (2009): 7-21.

7 ebrary, "2008 Global Student E-book Survey,” (2008), 18. http://www.ebrary.com/corp/collateral/en/Survey/ebrary_student_survey_2008.pdf (accessed June 29, 2009).

${ }^{8}$ Levine-Clark, 292.

${ }^{9}$ Gregory, 269.

${ }^{10}$ Yen-Yu Kang, Mao-Jiun J. Wang, and Rungtai Lin, “Usability Evaluation of E-books,” Displays 30 (2009): 4952; Levine-Clark, 297.

${ }^{11}$ Linda Bennett and Monica Landoni, "E-books in Academic Libraries,” Electronic Library 23 (2005): 9; ebrary, 8.

${ }^{12}$ Levine-Clark, 289.

${ }^{13}$ Bennett and Landoni, 14.

${ }^{14}$ Noorhidawati Abdullah and Forbes Gibb, "Students' Attitudes Towards E-books in a Scottish Higher Education Institute: Part 1," Library Review 57 (2008): 593-605.

${ }^{15}$ Leo Appleton, "The Use of Electronic Books in Midwifery Education: The Student Perspective," Health Information and Libraries Journal 21 (2004): 245-52; Levine-Clark, 297; Rajiv Nariani, "E-books in the Sciences: If We Buy It Will They Use It?" Issues in Science and Technology Librarianship (Fall 2009), http://www.istl.org/09-fall/article3.html (accessed March 26, 2010).

${ }^{16}$ Ruth Wilson, Monica Landoni and Forbes Gibb, "The WEB Book Experiments in Electronic Textbook Design," Journal of Documentation 59 (2003): 454-77.

${ }^{17}$ Ruth Wilson and Monica Landoni. EBONI: Electronic textbook design guidelines, (March 23, 2002). http://ebooks.strath.ac.uk/eboni/guidelines/ (accessed July 28, 2009).

${ }^{18}$ Abdullah and Gibb, "Students' Attitudes Part 1", 593-605; Abdullah and Gibb, "Students' Attitudes Towards Ebooks in a Scottish Higher Education Institute: Part 2," Library Review 57 (2008): 676-89; Abdullah and Gibb, "Students' Attitudes Towards E-books in a Scottish Higher Education Institute: Part 3," Library Review 58 (2009): 17-27.

${ }^{19}$ Peter Hernon et al., "E-book Use by Students: Undergraduates in Economics, Literature, and Nursing," The Journal of Academic Librarianship 33 (2007): 3-13. 
${ }^{20}$ K. Anders Ericsson and Herbert A. Simon, Protocol Analysis: Verbal Reports as Data, Rev. ed. (Cambridge, Mass.: MIT Press, 1992).

${ }^{21}$ Ericsson and Simon, 82-3.

${ }^{22}$ Deborah Cotton and Karen Gresty, "Reflecting on the Think-Aloud Method for Evaluating E-learning," British Journal of Educational Technology 37 (2006): 45-54.

${ }^{23}$ The University of Western Ontario is one of Canada's largest and oldest universities, with approximately 30,000 undergraduate and graduate students. Through its twelve Faculties and Schools and four affiliated colleges, Western offers more than 400 different majors, minors, and specializations.

${ }^{24}$ The Allyn \& Betty Taylor Library also supports the Faculties of Engineering and Health Sciences, and the Schulich School of Medicine and Dentistry.

${ }^{25}$ Kimball, Ives and Jackson, 15-28.

${ }^{26}$ Janice M. Morse, “The Significance of Saturation,” Qualitative Health Research 5 (1995): 147-149.

${ }^{27}$ Janice M. Morse, “Determining Sample Size,” Qualitative Health Research 10 (2000): 3-5.

${ }^{28}$ Wilson, Landoni and Gibb, 457.

${ }^{29}$ Since the Taylor Library has acquired many e-books through the Electronic Book Library (EBL) platform, this was the most convenient platform to use for the study.

${ }^{30}$ Virginia Braun and Victoria Clarke, "Using Thematic Analysis in Psychology," Qualitative Research in Psychology 3 (2006): 77-101. The six steps outlined by Braun and Clarke are: (1) get familiar with the data, (2) generate initial codes, (3) search for themes, (4) review themes, (5) define and name themes, and (6) produce the report.

${ }^{31}$ Oxford English Dictionary Online, s.v. "Linear," http://dictionary.oed.com/cgi/entry/50133588? (accessed July 30, 2009).

${ }^{32}$ Hernon et al., 7.

${ }^{33}$ Pei Fen Chong, Yan Peng Lim, Siew Woei Ling, “On the Design Preferences for Ebooks," IETE Technical Review 26 (2009): 213-222. http://tr.ietejournals.org/text.asp?2009/26/3/213/50706 (accessed March 25, 2010).

${ }^{34}$ Veronica Liesaputra and Ian H. Witten, “Seeking Information in Realistic Books: A User Study,” (2008): 29-38.

${ }^{35}$ Wilson, Landoni and Gibb, 473.

${ }^{36}$ Ibid, 454.

${ }^{37}$ Abdullah and Gibb, "Students' Attitudes Part 3," 25-6.

${ }^{38}$ Wilson, Landoni and Gibb, 471. 